\title{
Breast-feeding: matching supply with demand in human lactation
}

\author{
BY C. J. WILDE ${ }^{1}$, A. PRENTICE ${ }^{2}$ AND M. PEAKER ${ }^{1}$ \\ ${ }^{1}$ Hannah Research Institute, Ayr KA6 5HL \\ ${ }^{2}$ MRC Dunn Nutrition Unit, Cambridge CB4 $1 X J$
}

The potentially conflicting nutritional demands of parent and offspring during lactation may be considered across animal species in terms of cost-benefit analysis of parental investment. Based on Trivers' (1974) kinship theory, Peaker (1989) proposed that parents invest in their young to an extent which increases survival of the present offspring, but not necessarily to an extent which would decrease the parent's ability to invest in other offspring, including those not yet born. When the cost to the mother potentially compromises the parent's ability to produce future offspring, then she may choose to discontinue that investment. At one level, this investment is determined genetically: there is ample evidence that the time-course of lactation and the upper limit to milk production is set by the mother. The system, on the other hand, must be able to exploit unexpected natural advantages or cope with modest set-backs. This is certainly the case: the rate of milk secretion and duration of lactation varies with nutritional state. Thus, when nutrition is not limiting, and breeding does not have to be fitted into a tight seasonal window, the young will benefit accordingly. When food is in short supply, the outcome of the investment analysis is more complicated. Some species, such as rodents, may kill some or all of their litter, choosing instead to invest in the next pregnancy and lactation. In other species with long gestation periods, and a long-term commitment to the offspring, the mother may continue to favour the offspring despite the short-term disadvantage she may incur.

The latter is the case in breast-feeding mothers. For example, despite considerable nutritional hardship, Gambian mothers produced as much milk as a comparable group of UK mothers (Prentice et al. 1986). Test-weighing measurements of milk yield indicated that Gambian infants failed to thrive not because of insufficient milk production by their mothers, but because of a higher incidence of disease, particularly during the rainy season. Therefore, human mothers usually continue to invest in their offspring despite becoming metabolically disadvantaged. There may be conflict between the need to produce milk and the mother's own metabolic requirements, but this is resolved in favour of the infant.

\section{INFLUENCE OF SUCKLING FREQUENCY ON MILK OUTPUT}

One factor which may allow Gambian mothers to optimize their rate of milk secretion is the frequency with which they suckle their infants. UK mothers usually breast-feed four to six times daily during established lactation, whereas Gambian mothers were observed to suckle their infants up to fifteen times daily (Prentice et al. 1986). Other studies of breast-feeding mothers have shown that more frequent suckling acts to stimulate the mother's milk production. It has long been recognized that milk output can be increased by placing another infant on the breast (Macy et al. 1930). More recent studies have shown that daily expression of extra milk increases milk output (Dewey \& Lönnerdal, 
1986) and have demonstrated a correlation between breast-feeding frequency and milk production (Prentice et al. 1986). Indeed, it has become clear that milk output is regulated to match the infant's demand, and is signalled to the breast by the frequency and completeness of milk removal (for review, see Hartmann et al. 1994).

The relationship between milk removal and the rate of milk secretion has been investigated in lactating goats, where milking frequency, completeness of milking and rate of milk production could be determined accurately and the mechanism investigated with relative ease in tissue and cell culture. The local nature of the response of milk secretion to milk removal was characterized in lactating goats. Briefly, milking one gland of a goat's udder more frequently, three times instead of twice daily, increased the rate of milk secretion in that gland only, indicating that the response could not be attributed to systemic factors (Henderson et al. 1983). Changes in gland distension or intra-mammary pressure exerted by stored milk also could not account for the effect of frequent milking. This was demonstrated by milking one gland of the udder three times instead of twice daily, but at the extra third milking replacing the volume of milk removed by an equal volume of isosmotic sucrose. In this way, the gland was subjected to more frequent milk removal, while maintaining the same pattern of gland distension and relaxation as with normal twice daily milking. Sucrose replacement did not prevent stimulation of milk secretion by the extra milking (Henderson \& Peaker, 1984). Therefore, it was not the physical presence of stored milk which was important, but actual removal of milk from the gland. This experiment pointed to the involvement of a chemical mechanism, and suggested that milk may contain an inhibitor of milk secretion.

\section{IDENTIFICATION OF INHIBITORS OF MILK SECRETION IN GOAT'S AND} HUMAN MILK

We have used a rabbit mammary explant bioassay to test goat's milk fractions for their ability to inhibit the synthesis of milk constituents. Initial results with relatively crude milk fractions indicated the presence of such a factor. Inhibitory activity in defatted milk fractionated with the whey proteins rather than the caseins and, within the whey, inhibition was associated with constituents of $M_{r} 10000-30000$, based on their passage through or retention by ultrafiltration membranes (Wilde et al. 1987). The active constituent was subsequently purified by conventional FPLC. Fractions obtained by anion-exchange chromatography were tested in the bioassay and a single fraction eluting as the third major $A_{280}$ peak was found to inhibit both casein and lactose synthesis significantly. None of the other fractions had any consistent effect. Resolution of peak three by chromatofocusing identified three components, one of which contained all the inhibitory activity present in the starting material. Based on bioassay activity, this purification scheme resulted in a 40000 -fold purification of the inhibitor compared with unfractionated whey (Wilde et al. 1995). The inhibitory protein has a molecular weight by gel filtration of $\mathrm{M}_{\mathrm{r}} 7600$, and chemical deglycosylation by trifluoromethanesulphonic acid treatment reduced this by approximately 1000 , indicating that the inhibitor is a glycoprotein. It has an N-terminal amino acid sequence unrelated to other milk proteins. Therefore, in view of its novelty and biological activity we have named the protein FIL, feedback inhibitor of lactation.

A similar approach has been used to determine if human milk contains a similar inhibitory protein. Initial experiments indicated that a $M_{r} 6000-30000$ fraction of human 
whey protein, like the same fraction from goat's milk, inhibited lactose and casein synthesis in the rabbit explant bioassay (Prentice et al. 1989). This whey fraction was subjected to anion-exchange chromatography, and again one of the fractions, and only one, inhibited lactose and casein synthesis when tested in the rabbit explant bioassay. Chromatofocusing indicated that this fraction contained one predominant protein component, which accounted for all the inhibitory activity (C. J. Wilde and A. Prentice, unpublished results). The inhibitory human-milk protein bears a number of structural similarities to the caprine FIL, i.e. it also is a small, acidic, whey protein. It also cross-reacts in ELISA with an antibody which is specific for the caprine inhibitor. Therefore, based on its bioassay activity and these preliminary indications of structural and immunological relatedness to the caprine protein, this approach appears to have identified a human counterpart of FIL.

\section{MECHANISM OF FEEDBACK INHIBITION}

Caprine FIL is synthesized by the secretory epithelial cells of the mammary tissue. This was confirmed in goat mammary epithelial cells cultured on a reconstituted basement membrane (Engelbreth-Holm-Swarm matrix), a situation in which the cells become organized in multicellular structures ('mammospheres') reminiscent of alveoli in the lactating tissue (Barcellos-Hoff et al. 1989; Hurley et al. 1994). The epithelial cells also become polarized and secrete milk proteins vectorially into a closed lumen within the mammospheres. We found that FIL, along with casein and $\alpha$-lactalbumin, was secreted preferentially into this lumen space (Wilde et al. 1995). This suggests that in vivo the inhibitor is secreted preferentially, perhaps exclusively, into milk. It also indicates that feedback inhibition is an autocrine mechanism: the inhibitor is synthesized by the secretory epithelial cells on which it then exerts its effect.

How does FIL exert its inhibitory effect on the mammary epithelial cell? Since milk secretion can be inhibited by addition of FIL to milk in the gland (Wilde et al. 1995), we presumed that the protein acts through a specific cell-surface receptor. Preliminary evidence for a receptor-mediated mechanism has been obtained by ligand binding to mouse mammary-membrane preparations (C. H. Knight and C. J. Wilde, unpublished results), but the signal transduction triggered by receptor occupancy has not been characterized. However, it appears that its primary effect is to disrupt movement of milk constituents through the secretory pathway at the level of traffic from endoplasmic reticulum (ER) to Golgi. Using antibodies against the trans-Golgi marker TGN-38 we observed that FIL treatment of lactating mammary epithelial cells resulted in dispersal of the TGN from its normal peri-nuclear location to a fragmented distribution through the cytoplasm (Rennison et al. 1993). Electron microscopy also suggested that FIL resulted in a marked change in the morphology of the ER. Instead of the extensive, regulararranged ER typical of the fully-lactating cell, the ER of FIL-treated cells became irregular, vesiculated and in places swollen. These effects, however, were fully reversible within $1 \mathrm{~h}$ of FIL removal (Rennison et al. 1993). This mechanism of action would explain the protein's ability to regulate milk secretion coordinately in vivo. FIL injection inhibited milk secretion without affecting milk composition, as indeed was the case when autocrine inhibition was manipulated by frequency or completeness of milking. It would also explain some of the longer-term effects of milk removal on mammary cell differentiation (Wilde et al. 1990), which appear to be related to the ability of FIL to 
decrease the proportion of prolactin, and possibly other hormone receptors on the surface of the mammary epithelial cell, so lowering their sensitivity to the circulating hormone (Bennett et al. 1990).

\section{CHARACTERISTICS OF AUTOCRINE INHIBITION}

The mechanism of autocrine inhibition in human lactation has only recently come under investigation. Therefore, to discuss the mechanism of action of FIL it is necessary to consider again the goat inhibitory protein. Goat FIL, identified by tissue culture bioassay, inhibited milk secretion in a temporary and dose-dependent manner when introduced back into the gland of lactating goats through the teat canal (Wilde et al. 1995). Both the degree and duration of inhibition were dependent on the dose injected. With low doses, inhibition was relieved within $24 \mathrm{~h}$ of injection, which took place after the afternoon milking. Higher doses, however, inhibited milk secretion for up to $3 \mathrm{~d}$. As with changes in milking frequency, intra-ductal injection had no effect on gross milk composition, suggesting that the inhibitor was acting on all milk constituents equally.

The dose-dependence of the effect of FIL in vivo (Wilde et al. 1995) and in vitro (Wilde et al. 1987) suggests that the inhibitor's concentration in milk increases as milk accumulates, so that the rate of milk secretion is reduced as the gland fills. Conversely, the concentration of FIL should decrease after milking in order to re-establish an optimal rate of milk secretion. Thus, frequent milking would stimulate milk secretion by limiting the accumulation of inhibitory protein, whereas infrequent milking would reduce milk yield by increasing the amplitude of changes in the concentration of FIL in milk. Intra-ductal injection of FIL then mimics the effect of infrequent milking. The predicted kinetics of autocrine inhibition, however, are complicated by the presence of residual milk left in the gland after milking. According to our predictions, residual milk contains a high concentration of FIL, but this high concentration cannot persist indefinitely, since it would prevent cyclical changes in autocrine inhibition and milk secretion rate as milk accumulates and is removed. Whatever the mechanism involved, if these predictions are correct, relief from autocrine inhibition should be slower in glands which contain more residual milk. The larger the residual alveolar milk volume, the more residual milk there is to be diluted or metabolized, and the lower the mean rate of milk secretion should be in that gland. This relationship has been demonstrated in lactating goats: the rate of milk secretion is inversely related to the fraction of milk left in the gland after milking, and the relationship persists with time after milking (Peaker \& Blatchford, 1988). In other words, it is independent of the volume of milk in the gland at the time of milk removal.

Together, this work in lactating goats suggests that it is the concentration of active inhibitor in the alveolar lumen at any time which determines the rate of milk secretion of each gland and its response to changes in milking frequency. It also emphasizes that the lumen FIL concentration is intimately dependent on the completeness of milking. Completeness of milking is a function of, in part, the milk ejection reflex, but just as importantly, a function of the anatomy of the mammary gland. Those goat mammary glands which retain more milk do so because they tend to store more of their milk in the alveoli of the gland rather than in the large cisternal space (Knight et al. 1989). In other words, a high alveolar volume:cisternal volume ratio tends to produce a higher residual milk volume and a lower mean rate of milk secretion.

It is not yet known how autocrine inhibition in residual milk is relieved, nor how 
changes in inhibitor concentration are achieved during milk accumulation, but it is unlikely that they occur through a change in the rate of inhibitor secretion, since this would require that it be regulated independently of other milk constituents. An alternative possibility is that FIL is the result of, or is susceptible to, processing after secretion. In either case, first-order metabolism in the alveolar lumen would bring about an increasing concentration during milk accumulation, even though FIL was being secreted at a constant rate relative to other milk constituents. This may explain the presence in milk of other milk proteins structurally related to FIL but inactive in the bioassay. If FIL is the product of, or is susceptible to, first-order metabolism after secretion, this would also act to dilute or neutralize inhibitor in residual milk, re-establishing an optimal rate of milk secretion.

Translating these predictions to other species, one would expect that those species which do not possess a mammary cistern (and so store most if not all of their milk in the ducts and alveolar lumena of the mammary gland) will exhibit a rate of milk secretion which is especially dependent on the degree to which the gland is emptied at each suckling or milking. A consideration of human mammary anatomy indicates that the breast-feeding mother is in such a situation, and the importance of gland emptying in regulation of breast-milk secretion has been established in studies by Hartmann and colleagues (Daly et al. 1992, 1993). Using a computerized breast measurement system (Daly et al. 1992) they demonstrated that the baby rarely takes all the milk available to it; the breast contains varying amounts of residual milk after most feeds. More than that, it has demonstrated a clear relationship between the degree of breast emptying and the rate of milk secretion in the next interfeed period (Daly et al. 1993). As a result, despite being within the same hormonal milieu, a mother's breasts may synthesize milk at different rates which are determined by the degree of breast emptying at the previous feed (Daly et al. 1993). Thus, milk removal, and by extrapolation autocrine regulation, may be the predominant factor regulating milk secretion in the breast-feeding mother. The regular presence of residual milk also indicates that most well-nourished breastfeeding mothers have the capacity for milk synthesis in excess of that needed by the infant. So, in most instances it would appear that the putative conflict between mother's and offspring's metabolic need is not critical.

\section{CONCLUSION}

In conclusion, studies of breast-feeding mothers in Australia (Daly et al. 1992, 1993) have provided evidence that the rate of milk secretion in breast-feeding mothers is regulated locally within each mammary gland. A key factor in this local regulation of breast-milk secretion is the degree to which the breast is emptied at each feed, a situation which is echoed in other species, including the dairy animal. In those species, including the goat and cow, local regulation of milk secretion by frequency and completeness of milking is through autocrine feedback inhibition by a milk protein. We have as yet no definitive evidence that this is also the case in human lactation. However, by tissueculture bioassay we have isolated a protein which is able to inhibit synthesis of milk constitutents in vitro and which is to some extent structurally related to the ruminant inhibitory proteins. Identification of this inhibitory protein suggests that the rate of milk secretion in breast-feeding mothers is under autocrine feedback inhibition. Thus, autocrine control of milk secretion operating independently in each breast, rather than 
endocrine control by galactopoietic hormones, may serve to match the mother's milk output with the infant's demand for milk.

\section{REFERENCES}

Barcellos-Hoff, M. H., Aggeler, J., Ram, T. G. \& Bissell, M. J. (1989). Functional differentiation and alveolar morphogenesis of primary mammary cultures on reconstituted basement membrane. Development 105, 223-235.

Bennett, C. N., Knight, C. H. \& Wilde, C. J. (1990). Regulation of mammary prolactin binding by secreted milk proteins. Journal of Endocrinology 121, Suppl., 141.

Daly, S. E. J., Kent, J. C., Huynh, D. Q., Owens, R. A., Alexander, B. F., Ng, K. C. \& Hartmann, P. E. (1992). The determination of short-term breast volume changes and the rate of synthesis of human milk using computerised breast measurement. Experimental Physiology 77, 79-87.

Daly, S. E. J., Owens, R. A. \& Hartmann, P. E. (1993). The short-term synthesis and infant-regulated removal of milk in lactating women. Experimental Physiology 78, 209-220.

Dewey, K. G. \& Lönnerdal, B. (1986). Infant self-regulation of breast milk intake. Acta Paediatrica Scandinavica 75, 893-898.

Hartmann, P. E., Atwood, C. S., Cox, D. B. \& Daly, S. E. J. (1994). Endocrine and autocrine strategies for the control of lactation in women and sows. In Intercellular Signalling in the Mammary Gland, pp. 203-226 [C. J. Wilde, M. Peaker and C. H. Knight, editors]. New York: Plenum Publishing Company Limited.

Henderson, A. J., Blatchford, D. R. \& Peaker, M. (1993). The effect of milking thrice instead of twice daily on milk secretion in the goat. Quarterly Journal of Experimental Physiology 68, 645-652.

Henderson, A. J. \& Peaker, M. (1984). Feedback control of milk secretion in the goat by a chemical in milk. Journal of Physiology 351, 39-45.

Hurley, W. L., Blatchford, D. R., Hendry, K. A. K. \& Wilde, C. J. (1994). Extracellular matrix and mouse mammary cell function: comparison of substrata in culture. In Vitro Cellular Development Biology 30A, 529-538.

Knight, C. H., Brosnan, T., Wilde, C. J. \& Peaker, M. (1989). Evidence for a relationship between gross mammary anatomy and the increase in milk yield obtained during thrice daily milking in goats. Journal of Reproduction and Fertility, Abstract Series 3, 32.

Macy, I. G., Hunscher, H. A., Donelson, E. \& Nims, B. (1930). Human milk flow. American Journal of Diseases in Children 39, 1186-1204.

Peaker, M. (1989). Evolutionary strategies in lactation: nutritional implications. Proceedings of the Nutrition Society 48, 53-57.

Peaker, M. \& Blatchford, D. R. (1988). Distribution of milk in the goat mammary gland and its relation to the rate and control of milk secretion. Journal of Dairy Research $\mathbf{5 5}, 41-48$.

Prentice, A., Addey, C. V. P. \& Wilde, C. J. (1989). Evidence for local feedback control of human milk secretion. Biochemical Society Transactions 17, 122.

Prentice, A. M., Paul, A., Prentice, A., Black, A., Cole, T. \& Whitehead, R. (1986). Cross-cultural differences in lactational performance. In Maternal Environmental Factors in Human Lactation. Human Lactation 2, pp. 13-44 [M. Hamosh and A. S. Goldman, editors]. New York: Plenum Press.

Rennison, M. E., Kerr, M. A., Addey, C. V. P., Handel, S. E., Turner, M. D., Wilde, C. J. \& Burgoyne, R. D. (1993). Inhibition of constitutive protein secretion from lactating mouse mammary epithelial cells by FIL (feedback inhibitor of lactation), a secreted milk protein. Journal of Cell Science 106, 641-648.

Trivers, R. L. (1974). Social Evolution. Menlo Park, California: Benjamin/Cummings.

Wilde, C. J., Addey, C. V. P., Boddy, L. M. \& Peaker, M. (1995). Autocrine regulation of milk secretion by a protein in milk. Biochemical Journal 305, 51-58.

Wilde, C. J., Calvert, D. T., Daly, A. \& Peaker, M. (1987). The effects of goat milk fractions on synthesis of milk constituents by rabbit mammary explants and on milk yield in vivo. Biochemical Journal 242, 285-288.

Wilde, C. J., Knight, C. H., Addey, C. V. P., Blatchford, D. R., Travers, M., Bennett, C. N. \& Peaker, M. (1990). Autocrine regulation of mammary cell differentiation. Protoplasma 159, 112-117. 